\title{
The Prevalence and Severity of Dental Caries and Oral Hygiene Status of Asthmatic Children between the Age Group of 6 and 12 Years: A Cross-Sectional Study
}

\author{
Vasanthakumari Anandhan, R Bharathan, Karthik Venkataraghavan, Nayana V Reddy
}

\section{ABSTRACT}

Aim: To assess the prevalence and severity of dental caries and oral hygiene status of 6 to 12 years old children with bronchial asthma.

\begin{abstract}
Materials and methods: The study population consisted of 500 children between the age group of 6 and 12 years old, who were diagnosed with bronchial asthma and were under medication. DMFT score was assessed by WHO criteria (1997) and oral hygiene status was assessed by simplified oral hygiene index (OHI-S) by Greene and Vermillion (1964).

Results: The data was collected and analyzed using the SPSS package.15.6\% of females had good oral hygiene status when compared to males who almost had 12.6 and $20.8 \%$ of children who were in the category of moderate persistent asthma had decayed teeth whereas only $4 \%$ of children in severe persistent asthma category had experienced with decayed teeth.
\end{abstract}

Conclusion: Moderate persistent group of asthmatic children who were consuming orobronchodilator form of medication are found to have high prevalence of dental caries than dry powder and metered dose inhaler.

Keywords: Bronchial asthma, DMFT score, OHI score.

How to cite this article: Anandhan V, Bharathan R, Venkataraghavan K, Reddy NV. The Prevalence and Severity of Dental Caries and Oral Hygiene S tatus of Asthmatic Children between the Age Group of 6 and 12 Years: A Cross-Sectional Study. World J Dent 2012;3(3):250-254.

Source of support: $\mathrm{Nil}$

Conflict of interest: None declared

\section{INTRODUCTION}

Dental caries or early loss of teeth may lead to mal nutrition and other health problems. Caries and its complications affect the quality of life. Premature loss of primary teeth can result in a variety of adverse consequences, such as gastrointestinal disorders, esthetic and psychological problems. ${ }^{1,2}$

The prevalence pattern of dental caries not only varies with age, sex, socioeconomic status, race, geographical location, food habits and oral hygiene practices but also within the oral cavity. ${ }^{3}$

Dental caries in India is consistently increasing in prevalence and severity especially in children, today according to a number of investigators, 70 to $80 \%$ are suffering from this disease. The average number of decayed, missing and filled teeth at the age of 6 to 12 years is about 4 in rural and 5 in urban areas. ${ }^{4,5}$ Dental caries is almost affected by many systemic diseases. In that bronchial asthma is one of the major systemic diseases which is commonly affecting children. ${ }^{6} \mathrm{~A}$ sthma has a worldwide prevalence rate of 2 to $33 \%$ in childhood, a period of development when the effects of chronic disease and long-term medication are of particular concern. ${ }^{7}$

Dental and other oral health problems are also frequent in this age group. Frequent oral inhalation of these sugar containing drugs combined with the decrease in salivary flow rate may contribute to the increase in the risk of caries. Consumption of cariogenic drinks, in an attempt to wash away the taste of the inhaled medication and to counter the desiccating effect of mouth breathing and the reduction in the salivary flow caused by beta 2 agonist, can also be a reason for the increase in the caries rate in asthmatics. ${ }^{8,9}$ Hence, the study was conducted to assess the prevalence and severity of dental caries and oral hygiene status of 6 to 12 years old children with bronchial asthma.

\section{MATERIALS AND METHODS}

The present study, was conducted in a private hospital exclusive for bronchial asthma and the study population consisted of 500 children between the age group of 6 and 12 years old, who were diagnosed with bronchial asthma and were under medication as advised by their physician. The survey commenced after a letter of information regarding the objective and procedure of the study was handed over to the concerned authority in advance and permission was obtained. The children were divided into 4 groups like intermittent, mild, moderate and severe as per the severity of asthma.

The clinical examination was carried out and details regarding the past medical history of bronchial asthma and frequency, dosage and form of medication, previous dental visit of the patient, diet histories, frequency and duration of brushing details were also collected from parents or legal guardian with the help of a structured questionnaire. A fter which the oral examination of asthmatic children was done using sterile instruments. 
The Prevalence and Severity of Dental Caries and Oral Hygiene Status of Asthmatic Children between the Age Group

DM FT score was assessed by WHO criteria (1997) and oral hygiene status by simplified oral hygiene index (OHI-S) by Greene and V ermillion (1964). All examinations were conducted by a single trained examiner and a trained recording clerk assisted the examiner in the survey. Participants received instructions related to oral hygiene maintenance at the end of the clinical examination.

\section{STATISTICAL ANALYSIS}

Data was analyzed by using SPSS (statistical packages for social sciences) for W indows XP. Interexaminer reliability and intraexaminer reliability was used to compare variables. A result of less than 0.005 was chosen as the statistical level of significance for all calculations.

\section{RESULTS}

The study population consisted of 500 asthmatic children between the age group of 6 and 12 years. Intraoral examination was carried out and the values were recorded using DM FT index (W HO Criteria- 1997) and simplified oral hygiene index (Greene and V ermillion-1964) (Table 1).

It is evident that $14.8 \%$ of male children and $22.8 \%$ of female children found to have decayed teeth. In contrast $13.6 \%$ of female children and $8.8 \%$ of male children were seem to have filled teeth (Table 2).

It was observed that $12.2 \%$ of male children and $15.6 \%$ of female children were found to have good oral hygiene while $12.6 \%$ of male children and $26 \%$ of female children had fair oral hygiene (Table 3, Graph 1 ).

Out of 500 children, it was found that $20.8 \%$ of the children in the moderate persistent category had high prevalence of dental caries, whereas $2 \%$ of the children in the intermittent category were found to have low prevalence of dental caries (Table 4).

In the intermittent group, $6.2 \%$ of them were found to have good oral hygiene, while $4.6 \%$ of them had fair oral hygiene (Graph 2).

Table 1: Dental caries status based on gender distribution

\begin{tabular}{|c|c|c|c|c|c|}
\hline Sex & Subject & Decayed & Filling & Missing & Sound \\
\hline \multirow[t]{2}{*}{ Male } & Number & 74 & 44 & 14 & 54 \\
\hline & Percentage & 14.8 & 8.8 & 2.8 & 10.8 \\
\hline \multirow{2}{*}{ Female } & Number & 114 & 68 & 28 & 87 \\
\hline & Percentage & 22.8 & 13.6 & 5.6 & 17.4 \\
\hline \multirow[t]{2}{*}{ Total } & Number & 188 & 112 & 42 & 141 \\
\hline & Percentage & 37.6 & 22.4 & 8.4 & 28.2 \\
\hline
\end{tabular}

Table 2: Oral hygiene status based on gender distribution

\begin{tabular}{cllll}
\hline \multirow{2}{*}{ Gender } & Subject & \multicolumn{2}{c}{ OHIS } & Good \\
\cline { 3 - 4 } & & Fair & 61 & 193 \\
Male & Number & 63 & 12.2 & 38.6 \\
\multirow{2}{*}{ Female } & Percentage & 12.6 & 78 & 99 \\
& Number & 130 & 15.6 & 19.8 \\
\hline \multirow{2}{*}{ Total } & Percentage & 26.0 & 139 & 168 \\
& Number & 193 & 27.8 & 33.6 \\
\hline
\end{tabular}

Table 3: Dental caries status based on severity of asthma

\begin{tabular}{|c|c|c|c|c|c|}
\hline \multirow[t]{2}{*}{ Dental caries } & \multirow[t]{2}{*}{ Subject } & \multicolumn{4}{|c|}{ Severity of asthma } \\
\hline & & Intermittent & Mild persistent & Moderate persistent & Severe persistent \\
\hline Decayed & $\begin{array}{l}\text { Number } \\
\text { of children } \\
\text { Percentage }\end{array}$ & $\begin{array}{l}10 \\
2\end{array}$ & $\begin{array}{l}54 \\
10.8\end{array}$ & $\begin{array}{l}104 \\
20.8\end{array}$ & $\begin{array}{l}20 \\
4\end{array}$ \\
\hline Filling & $\begin{array}{l}\text { Number } \\
\text { of children } \\
\text { Percentage }\end{array}$ & $\begin{array}{l}10 \\
2\end{array}$ & $\begin{array}{l}20 \\
4\end{array}$ & $\begin{array}{l}66 \\
13.2\end{array}$ & $\begin{array}{l}16 \\
3.2\end{array}$ \\
\hline Missing & $\begin{array}{l}\text { Number } \\
\text { of children } \\
\text { Percentage }\end{array}$ & $\begin{array}{l}5 \\
1\end{array}$ & $\begin{array}{l}5 \\
1\end{array}$ & $\begin{array}{l}27 \\
5.4\end{array}$ & $\begin{array}{l}5 \\
1\end{array}$ \\
\hline Sound & $\begin{array}{l}\text { Number } \\
\text { of children } \\
\text { Percentage }\end{array}$ & $\begin{array}{l}27 \\
5.4\end{array}$ & $\begin{array}{l}48 \\
9.6\end{array}$ & $\begin{array}{l}47 \\
9.4\end{array}$ & $\begin{array}{l}19 \\
3.8\end{array}$ \\
\hline
\end{tabular}




\begin{tabular}{|c|c|c|c|c|c|}
\hline \multirow[t]{2}{*}{$\mathrm{OHIS}$} & \multirow[t]{2}{*}{ Subject } & \multicolumn{4}{|c|}{ S everity of asthma } \\
\hline & & Intermittent & Mild persistent & Moderate persistent & Severe persistent \\
\hline Fair & $\begin{array}{l}\text { Number } \\
\text { of children } \\
\text { Percentage }\end{array}$ & $\begin{array}{l}23 \\
4.6\end{array}$ & $\begin{array}{l}64 \\
12.8\end{array}$ & $\begin{array}{l}87 \\
17.4\end{array}$ & $\begin{array}{l}19 \\
3.8\end{array}$ \\
\hline Good & $\begin{array}{l}\text { Number } \\
\text { of children } \\
\text { Percentage }\end{array}$ & $\begin{array}{l}31 \\
6.2\end{array}$ & $\begin{array}{l}65 \\
13.0\end{array}$ & $\begin{array}{l}38 \\
7.6\end{array}$ & $\begin{array}{l}5 \\
1.0\end{array}$ \\
\hline Poor & $\begin{array}{l}\text { Number } \\
\text { of children } \\
\text { Percentage }\end{array}$ & $\begin{array}{l}0 \\
0\end{array}$ & $\begin{array}{l}0 \\
0\end{array}$ & $\begin{array}{l}129 \\
25.8\end{array}$ & $\begin{array}{l}39 \\
7.8\end{array}$ \\
\hline Total & $\begin{array}{l}\text { Number } \\
\text { of children } \\
\text { Percentage }\end{array}$ & $\begin{array}{l}54 \\
10.8\end{array}$ & $\begin{array}{l}129 \\
25.8\end{array}$ & $\begin{array}{l}254 \\
50.8\end{array}$ & $\begin{array}{l}63 \\
12.6\end{array}$ \\
\hline
\end{tabular}

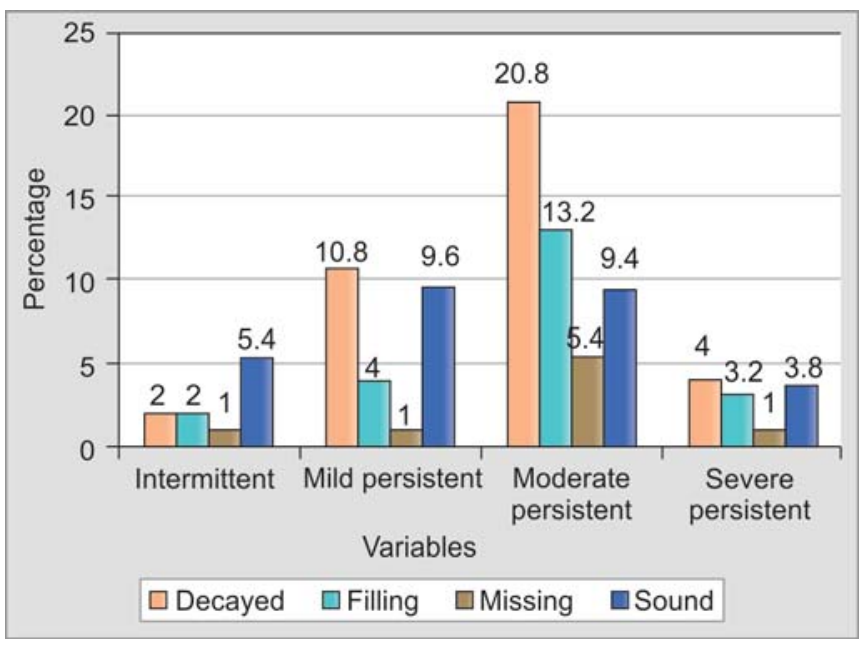

Graph 1: Dental caries status based on severity of asthma

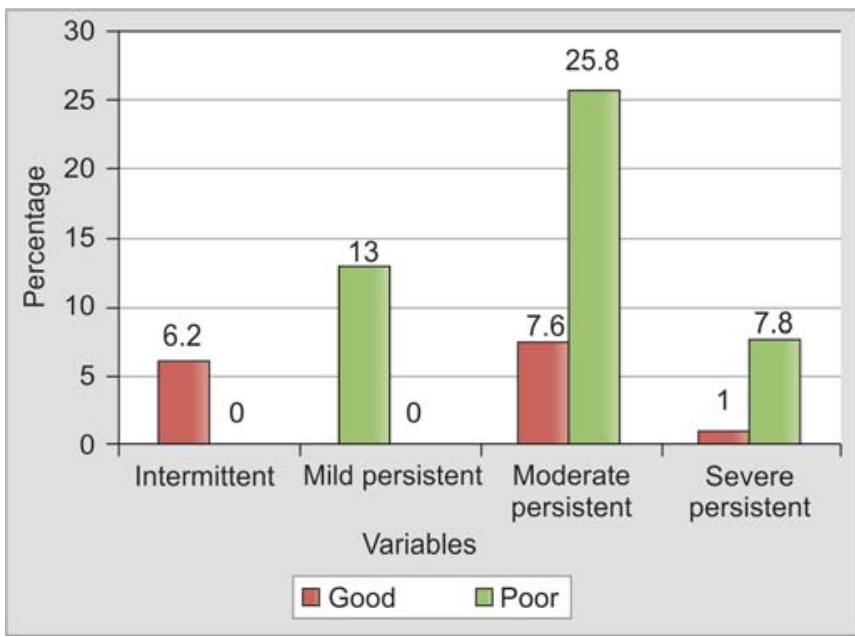

Graph 2: Oral hygiene status based on severity of asthma

In mild persistent group, $13 \%$ of the children were seen to have good oral hygiene, while $12.8 \%$ of the children had fair oral hygiene and in the moderate persistent group, 7.6\% of them w ere observed to have good oral hygiene and $17.4 \%$ of them had fair oral hygiene.
In the severe persistent group, $1 \%$ of the subjects were seen to have good oral hygiene and $3.8 \%$ of the subjects had fair oral hygiene. It was observed form this study that moderate and severe persistent groups had higher percentage of poor oral hygiene status.

\section{DISCUSSION}

A $n$ overall increase in the prevalence of dental caries was seen in the subjects of bronchial asthma. There may be numerous reasons for the higher prevalence of caries in asthmatic children. ${ }^{10}$

A large number of studies have considered asthma as a risk factor in the occurrence of dental caries. According to some reports, asthmatic patients suffer more from the two main oral diseases, caries and periodontal disease, than nonasthmatic subjects. ${ }^{11,12}$

A sthma had a worldwide prevalence rate of 2 to $33 \%$ in childhood, a period of development when the effects of chronic disease and long-term medication are of particular concern. Dental and other oral health problems are also frequent in this age group. ${ }^{13}$

In the present study, the results showed that about $15.6 \%$ of females had good oral hygiene status when compared to males who almost had $12.2 \%$.

Milano et al had conducted a study on prevalence of oral hygiene status in asthmatic children and he found $21.5 \%$ of females had good oral hygiene, which almost coincides this study. ${ }^{14}$

The results of this study showed that about $20.8 \%$ of children who were in the category of moderate persistent asthma had decayed teeth where as only $4 \%$ of children in severe persistent asthma category had decayed teeth.

Malin Stensson et al and Ida Anjomshoaa et al who found that the high prevalence of dental caries was seen in moderate persistent category of children and low prevalence 
The Prevalence and Severity of Dental Caries and Oral Hygiene Status of Asthmatic Children between the Age Group

of dental caries was seen in severe persistent asthma category, which clearly is in line with the results of this study. ${ }^{15,16}$

This present study showed about $17.6 \%$ of the children who were using metered dose inhaler had good oral hygiene status whereas $6.5 \%$ of children who were advised oral bronchodilator had a poor oral hygiene. It was interesting to see that the children who were using metered dose inhaler had a good oral hygiene status and inturn they had a least dental caries score. The brushing frequency alone does not help in maintaining oral hygiene. It should be in combination with proper brushing techniques, which can be incorporated in these children with various measures by creating awareness. ${ }^{17,18}$

The result of this study highlights the points that it is essential to develop individualized intensive preventive dental programs for asthmatic children according to their age, since they are at higher risk for dental caries.

Also due to increase attention given to their general asthmatic condition, parents may give little importance to oral hygiene procedures. The removal of plaque and debris from the teeth is a skill that can be mastered only when an individual has the dexterity to manipulate the toothbrush and understands the objectives of these activities. The success of good oral hygiene reflects the skill, dedication, and motivation of an individual or those who are responsible for it. The brushing frequency alone does not help in maintaining oral hygiene. It should be in combination with proper brushing techniques, which can be incorporated in these children with various measures by creating awareness. ${ }^{19,20}$

\section{CONCLUSION}

The results of the study reveals that the inhalers used for asthma and the drugs used in it are seen as a risk factor for dental caries and poor oral hygiene status. Proper oral hygiene instructions should be given to the children as these drugs are acidic in nature and often have side effects, the children should be persuaded to get into the habit of rinsing the mouth immediately after using the inhaler with basic mouth rinses which has neutral pH, such as liquid antacids, sodium bicarbonate in water, milk or neutral sodium fluoride mouth rinses. Children should also be instructed not to brush their teeth immediately after exposure to acids as it may damage the already weakened enamel. The parents of the children with asthma should be educated and informed about the nature of this medical condition and how it increases their susceptibility to dental caries. Therefore special oral health attention should be provided to asthmatic children to improve their quality of life. Moreover, it can be recommended that dentists should be included in the multiprofessional team involved in asthmatic assistance.

\section{REFERENCES}

1. Cigdem Sag, Feyza Otan Ozden, Dent SC. The effects of combination treatment with a long acting B2-agonist and a corticosteroid on salivary flow rate, secretory immunoglobulin $A$, and oral health in children and adolescents with moderate asthma: A 1-month single-blind clinical study. Clin Ther 2007;29:2236-42.

2. L aurikainen $K, K$ uusisto $P$. Comparison of the oral health status and salivary flow rate of asthmatic patients with those of nonasthmatic adults - results of a pilot study. Allergy 1998; 53:316-19.

3. Lenander-L umikari M, Laurikainen K, Kuusisto P, Vilja P. Stimulated salivary flow rate and composition in asthmatic and nonasthmatic adults. A rch Oral Biol 1998;43:151-56.

4. MCDerra EJ, Pollard MA, Curzon ME. The dental status of asthmatic British school children. Pediatr Dent 1998;20: 281-87.

5. M eldrum AM, Thomson WM, Drummond BK, Sears MR. Is asthma a risk factor for dental caries? Finding from a cohort study. Caries Res 2001;35:235-39.

6. M onica Paganini M, Cassia Cilele Dezan. Dental caries status and salivary properties of asthmatic children and adolescents. International J ournal of Pediatric Dentistry 2011;21:185-91.

7. Robert A. Bagramian, Franklin Garcia - Gody, A nthony R. The global increase in dental caries. A pending public health crisis. A merican J Dent 2009;22:3-8.

8. Shashikiran ND, R eddy V V. Effect of antiasthmatic medication on dental disease: D ental caries and periodontal disease. J Indian Soc Pedod Prev Dent 2007;25:65-68.

9. Steinbacher DM, Glick M. The dental patient with asthma. An update and oral health considerations. Journal of American Dental Association 2001;132:1229-39.

10. Tewari S. Caries experience in 3 to 7 years old children in Haryana (India). J Indian Soc Pedod Prev Dent 2001;19(2): 52-56.

11. Thomas M, Parolia A, K undabala M, V ikram M. A sthma and oral health: A review. A ustralian Dental Journal 2010;55: 128-33.

12. T urkistani J, Farsi N, A lmushayt A, A laki S. Caries experience in asthmatic children: A review of literature. J Clin Pediatr D ent 2010;35:1-8.

13. W ogelius $P$, Poulsen $S$, Sorensen $H$. U se of asthma-drugs and risk of dental caries among 5 to 7 years old Danish children: $\mathrm{A}$ cohort study. Community Dent Health 2004;21:207-11.

14. M ilano M . Increased risk for dental caries in asthmatic children. Tex Dent J 1999;116:35-42.

15. Stensson M , W endt LK, K och G, Nilsson M , Oldaeus G, B irkhed D. O ral health in preschool children with asthma followed from 3 to 6 years. Int J Paediatr Dent 2010;20:165-72.

16. Ida A njomsoaa, M argaret Cooper, A lexdre Vieira. Caries is associated with asthma and epilepsy. Eur J Dent 2009;3: 297-303.

17. W ong M C, L O E, Schwarz E, Zhang HG. O ral health status and oral health behaviors in Chinese children. J Dent Res 2001;80:1459-65.

18. Zerfowski M, Koch ML Niekusb U. Caries prevalence and treatment needs of 7 to 10 years old school children in South Western Germany. Community Dent Oral Epidemiol 1997;25:348-51. 
19. ZhuJ F, Hidalgo HA, H olmgreen W C, R edding SW, HuJ, Henry RJ. Dental management of children with asthma. Pediatr Dent 1996;18:363-70.

20. Dash J, Sahoo P, B huyan S, Sahoo S. Preval ence of dental caries and treatment needs among children of Cuttack (O rissa). J Indian Soc Pedo Prev Dent 2002;20:139-43.

\section{ABOUT THE AUTHORS}

\section{Vasanthakumari Anandhan (Corresponding Author)}

Professor and Head, Department of Pedodontics and Preventive Dentistry, Sri Ramachandra U niversity, Chennai, Tamil Nadu, India Phone: 9443615196, e-mail: vkpedo@ gmail.com

\section{R Bharathan}

Postgraduate Student, Department of Pedodontics and Preventive Dentistry, Sri Ramachandra University, Chennai, Tamil N adu, India

\section{Karthik Venkataraghavan}

Professor and Head, Department of Pedodontics and Preventive Dentistry, College of Dental Sciences and Research Centre A hmedabad, Gujarat, India

\section{Nayana V Reddy}

Postgraduate Student, Department of Pedodontics and Preventive Dentistry, Sri Ramachandra University, Chennai, Tamil N adu, India 